Recebido em 03/2019. Aceito para publicação em 08/2019.

\title{
AVALIAÇÃO DE PROTEÍNAS DE CHOQUE TÉRMICO EM CÉLULAS NEOPLÁSICAS DE LARINGE (HEP-2) APÓS TRATAMENTO FOTODINÂMICO
}

\section{EVALUATION OF HEAT SHOCK PROTEINS IN LARINX NEOPLASTIC CELLS (HEP-2) AFTER PHOTODYNAMIC TREATMENT}

\author{
Cristina Pacheco Soares ${ }^{1}$ \\ Marilia Hidalgo Uchôas ${ }^{2}$ \\ Bruno Henrique Godoi ${ }^{3}$ \\ Carlos Dailton Guedes de Oliveira Moraes ${ }^{4}$
}

Resumo: Proteínas de choque térmico (HSP) são moléculas intracelulares multifuncionais que, eventualmente, podem estar envolvidas na malignização celular. Terapia fotodinâmica (TFD) pode levar à redução do tumor e vasos sanguíneos ao redor. Objetivo foi avaliar ação da TFD sobre as HSPs em células neoplásicas de carcinoma de laringe humana (HEp-2). As células foram irradiadas com LED a 660 $\mathrm{nm}, 5 \mathrm{~J} / \mathrm{cm}$ 2, $70 \mathrm{~mW}$, por 3 minutos e 20 segundos; incubadas por períodos de 24, 48 e 72 horas; após os períodos de incubação foi realizada a extração de proteínas e corrido gel de poliacrilamida para avaliação das proteínas por Western-Blotting. As células foram imunomarcadas com anticorpos anti-HSP27, antiHSP70 e anti-HSP90 e analisadas no microscópio confocal. A viabilidade celular foi avaliada pelo teste de cristal violeta. No gel de poliacrilamida foram identificadas bandas próximas a 27 kDa, 70 kDa e 90 kDa. Nas fotomicrografias observou-se redução do número de células após TFD, comprovado por teste de viabilidade (cristal violeta); e intensa marcação de HSPs após TFD, principalmente próximas ao núcleo. Concluiu-se que HSP27, HSP70 e HSP90 são muito produzidas em células HEp-2. TFD foi eficaz devido à redução do número de células e considerada opção viável para o tratamento dessa doença. Embora seja relatada a participação das HSPs 27, 70 e 90 como protetoras das células tumorais, nossos resultados indicam que a TFD ativa tais proteínas para a redução das células tumorais.

Palavras-chaves: Cultura de células; proteínas de choque térmico; LED; ftalocianina.

Abstract: Heat shock proteins (HSPs) are multifunctional intracellular molecules that may eventually be involved in cell malignancy. Photodynamic therapy (PDT) can lead to reduction of tumor and surrounding blood vessels. OBJECTIVE: To evaluate the effect of PDT on HSPs in neoplastic human laryngeal carcinoma cells (HEp-2). Cells were irradiated with LEDs at $660 \mathrm{~nm}, 5 \mathrm{~J} / \mathrm{cm} 2,70 \mathrm{~mW}$ for 3 minutos. and 20 seconds.; incubated for periods of 24, 48 and 72 hours; after the incubation periods the protein extraction and run-on polyacrylamide gel was performed to evaluate the proteins by Western Blotting. Cells were immunolabelled with anti-HSP27, anti-HSP70 and anti-HSP90 antibodies and analyzed on the confocal microscope. Cell viability was evaluated by the crystal violet test. In the polyacrylamide gel, bands close to $27 \mathrm{kDa}, 70 \mathrm{kDa}$ and $90 \mathrm{kDa}$ were identified. Photomicrographs showed a reduction in the number of cells after PDT, as confirmed by viability test (crystal violet); and intense marking of HSPS after PDT, especially close to the nucleus. It has been concluded that HSP27, HSP70 and HSP9O are very produced in HEp-2 cells. PDT was effective due to a reduction in the number of cells and considered a viable option for the treatment of this disease. Although the involvement of HSPs 27, 70 and 90 as protective of tumor cells is reported, our results indicate that PDT activates such proteins for the reduction of tumor cells. Keywords: Cell culture; heat shock proteins; LED; phthalocyanine.

\footnotetext{
${ }^{1}$ Doutora em Biociências e Biotecnologia. Docente na Universidade do Vale do Paraíba - Univap, Brasil. E-mail: cpsoares@univap.br.

2 Professor Auxiliar I da Universidade de Taubaté, Brasil. E-mail: ma.hidalgo.u@gmail.com.

${ }^{3}$ Graduado em Biomedicina, Universidade do Vale do Paraíba - Univap, Brasil. E-mail: bh-godoi@bol.com.br.

4 Graduado em Biomedicina, Universidade do Vale do Paraíba - Univap, Brasil. E-mail: carlosdailtongom@gmail.com.
} 


\section{INTRODUÇÃO}

A terapia fotodinâmica (TFD) é uma alternativa ao tratamento oncológico, que envolve a ação de um fotossensibilizante sob a incidência de luz e a presença de oxigênio molecular (ISSA; MANELA-AZULAY, 2010). Dessa reação resultam espécies reativas de oxigênio (EROs) que inviabilizam as células (SILVA et al., 2018; KIM et al., 2016). TFD é considerada uma técnica pouco invasiva, com boa seletividade e provoca baixa toxicidade nas células não alvo (SILVA, 2014), o que justifica 0 interesse por essa linha de tratamento. A TFD induz a autofagia, apoptose e necrose em células de câncer (YOON et al., 2010) e é importante que haja equilíbrio entre a apoptose e a autofagia, para que os efeitos da TFD sejam máximos (KIM et al., 2016). $\mathrm{O}$ uso de TFD pode resultar em resistência, dependendo do fotossensibilizante, da dose de luz e dos tipos de células utilizadas, e dentre os mecanismos de resistência à TFD, incluem-se enzimas antioxidantes, proteínas de resistência a múltiplos fármacos, vias anti-apoptóticas, expressão de HSPs e autofagia (CASAS et al., 2011). Nas células tumorais, TFD pode induzir a síntese de HSPs e proteínas reguladas por glicose (GRPs) (WOZNIAK et al., 2018), que viajam para a superfície da célula e agem como sinalizadores, estimulando resposta imunológica (ETMINAN et al., 2011). TFD pode ocasionar três efeitos antitumorais: (I) citotoxicidade; (II) danos aos vasos sanguíneos tumorais e (III) induzir reação inflamatória (AGOSTINIS et al., 2011). A citotoxicidade das EROs leva tanto à apoptose quanto à necrose (VAN STRATEN et al., 2017). A concentração de oxigênio molecular no tecido do tumor, a energia da fonte luminosa escolhida e a penetrabilidade do fotossensibilizante são fatores limitantes para o efeito de morte gerada pela TFD (LI et al., 2019). Sob ação da TFD, HSPs podem ser liberadas pelas células mortas e afetar reações imunológicas da mesma forma (WOZNIAK et al., 2018).

O câncer e os tratamentos antitumorais, por estressarem as células, induzem a produção de proteínas de choque térmico do inglês "Heat Shock Proteins" (HSPs) nas células sobreviventes, levando a mutações, que podem influenciar na progressão, malignização e metástase (KAPOOR; VAIDYA, 2013). As HSPs possuem vasta capacidade de aplicações clínicas para diferentes tratamentos (TÓTH; GOMBOS; SÁNTHA, 2015) por se comportarem como biomarcadores celulares (SEIGNEURIC et al., 2011). Em mamíferos, são classificadas conforme seu peso molecular: HSP100, HSP90, HSP70, HSP60, HSP40 e HSPs pequenas (TERRINCA, 2015), podem aumentar o potencial imunológico específico para os antígenos tumorais (GRANER et al., 2015). Elas também podem ser classificadas em: (I) chaperonas (SRIVASTAVA, 2002); (II) cross-priming (BLUM; WEARSCH; CRESSWELL, 2013); e (III) HSPs indutoras da inflamação (RADONS, 2016). HSPs possuem variadas funções dentro das células, maioria citoprotetoras. HSP27 é tumorigênica por agir como chaperona, confere capacidade de alterar atividades proteicas do ciclo celular, das quinases e de outras proteínas que estimulam o crescimento tumoral (JUHASZ et al., 2014). Na oncologia, HSP27 foi detectada no meio extra e intracelular, com papel anti-apoptótico 
pela interação com Bid ou citocromo $\mathrm{C}$, e contribui para a invasão e metástase do tumor (SEIGNEURIC et al., 2011). Elevados níveis de HSP27 foram encontrados no câncer de ovário, próstata e mama, correlacionando-se com mau prognóstico para pacientes com essas doenças (KHALIL et al., 2011; CALDERWOOD, 2010). Em um estudo citado por Seigneuric et al. (2011), com amostras de biópsia de pacientes com câncer de próstata, observou-se que a expressão de HSP27 no tecido foi regulada positivamente em comparação com os controles. HSP70 é cito protetora contra lesões induzidas pela TFD e tumorigênica (KUMAR et al., 2016). HSP70 é uma poderosa chaperona dependente de ATP, com propriedades anti-apoptóticas chave, considerada a HSP mais induzida pelo estresse, pode ser um biomarcador interessante porque sua super expressão no soro está associada a muitos tipos de câncer (SEIGNEURIC et al., 2011). Fragmentos de HSP70 expressos na membrana em linhagens celulares de câncer podem ser detectados por um anticorpo (STANGL et al., 2011). HSP90 interage com várias moléculas, atua no enovelamento e estabilização de proteínas do citoesqueleto, regulação do ciclo celular, diferenciação e apoptose, sendo considerada uma ferramenta terapêutica (TERRINCA, 2015). A HSP90 é uma chaperona ATP-dependente que tem sido muito estudado para a terapia anticâncer (JEGO et al., 2013) com inibidores segmentados. HSP90 é essencial para a estabilidade e função de muitas proteínas oncogênicas (TAIPALE; JAROSZ; LINDQUIST, 2010). Nos cânceres de mama invasivos, análises imuno-histoquímicas mostraram que a HSP90 foi abundantemente expressa em todas as amostras de tumor incluídas no estudo (SONG et al., 2010). Em consonância com esses resultados, foi sugerido que a super expressão de HSP90 no câncer de mama, no carcinoma hepatocelular, no câncer de bexiga e no câncer de ovário e os níveis elevados de HSP90 foram correlacionados com tumor de alto grau de malignidade, podendo ser um bom indicador de agressividade quando associada a outras HSPs (SEIGNEURIC et al., 2011).

HSPs também podem ser encontradas no meio extracelular (MULLER, 2018). Estudos, como os de Buttros (2018), Wozniak et al. (2018), Lu e Kakkar (2010), sugerem que HSPs extracelulares indicam morte ou liberação de conteúdo intracelular, funcionando como sinalizadoras de antígenos tumorais para o sistema imunológico, favorecendo a necrose da célula tumoral.

O objetivo foi avaliar as HSPs após TFD como uma alternativa ao tratamento de carcinoma de laringe humano (HEp-2), avaliando a presença das proteínas HSP27, HSP70 e HSP90 em células não tratadas e em células tratadas pela TFD.

\section{MATERIAIS E MÉTODOS}

\subsection{Linhagem celular}

Utilizou-se a linhagem HEp-2 (carcinoma de laringe humana), adquirida do Instituto Adolfo Lutz, São Paulo/SP, cultivadas no Laboratório de Dinâmica de 
Compartimentos Celulares, do IP\&D, da UNIVAP. As células foram cultivadas em garrafas de cultura com meio DMEM suplementado com $10 \%$ de Soro Fetal Bovino (SFB) e $1 \%$ de antibiótico e antimicótico (AA), incubadas em estufa a $37^{\circ} \mathrm{C}$ com $5 \%$ de $\mathrm{CO}_{2}$ até atingir uma concentração entre $3 \times 10^{6}$ e $4 \times 10^{6}$ células/garrafa (confluência), contadas com 0 auxílio do TAL/ ${ }^{\mathrm{TM}}$ Image-Based Cytometer Invitrogen ${ }^{\mathrm{TM}}$ (ThermoFischer Scientific- Waltham, Massachusetts, EUA).

\subsection{Grupos Experimentais}

- Grupo Controle: as células foram cultivadas em meio de cultura e não foram incubadas com o fotossensibilizante e nem irradiadas períodos de 24, 48 e 72 horas.

- Grupo Irradiado: as células foram irradiadas. Em seguida incubadas em meio de cultura nos períodos de 24,48 e 72 horas, sendo os parâmetros descritos no item irradiação.

- Grupo Fotossensibilizante: as células foram incubadas com 0 fotossensibilizante. Em seguida incubadas em meio de cultura nos períodos de 24 , 48 e 72 horas, sendo os parâmetros descritos no item fotossensibilizante.

- $\quad$ Grupo TFD: As células foram incubadas com o fotossensibilizante, a seguir foi realizado a irradiação. Em seguida, incubadas em meio de cultura nos períodos de 24, 48 e 72 horas. Os parâmetros estão descritos nos itens fotossensibilizante e irradiação.

\subsection{Plaqueamento}

Após a confluência da cultura, as células HEp-2 foram retiradas das garrafas com auxílio da solução de tripsina $0,1 \%$. Sendo então plaqueadas $1 \times 104$ células $/ \mathrm{mL}$ para os testes de viabilidade celular em microplacas de 24 poços, ou $1 \times 105$ células $/ \mathrm{mL}$ para os demais testes em microplacas de 96 poços, com meio de cultura DMEM suplementado com $10 \%$ de soro fetal bovino (SFB) para adesão das células em estufa a uma temperatura de $37^{\circ} \mathrm{C}$ e $5 \%$ de $\mathrm{CO} 2$, overnight.

\subsection{Fotossensibilizante}

Vinte e quatro horas após o plaqueamento das células HEp-2, o meio de cultura foi retirado e os poços foram lavados duas vezes com solução salina tampão fosfato (PBS) para remoção das células não aderidas. Em seguida, foi adicionado $200 \mu \mathrm{L}$ da solução de Alumínio Ftalocianina Tetrassulfonada $\left(\right.$ AIPCS $\left._{4}\right)$ a $10 \mu \mathrm{M}$ diluída em PBS e as células foram incubadas por 1 hora em estufa a uma temperatura de $37^{\circ} \mathrm{C}$ e $5 \%$ $\mathrm{CO}_{2}$. Ao término deste período, a solução de $\mathrm{AlPcS}_{4}$ foi retirada, então as células foram lavadas novamente duas vezes com PBS (MORAES et al., 2019). 


\subsection{Irradiação}

Após a lavagem das células com PBS para remoção do excesso de corante, foi adicionado $200 \mu \mathrm{L}$ de PBS em cada poço para o processo de irradiação. A irradiação foi realizada com o dispositivo LED’s Biopdi/Irrad-Led5 660 (Biopdi - São Carlos, São Paulo, Brasil) com 54 LEDs. Os parâmetros de irradiação são: comprimento de onda de $660 \mathrm{~nm} \pm 5 \mathrm{~nm}$; densidade de energia de $5 \mathrm{~J} / \mathrm{cm} 2$; potência de $70 \mathrm{~mW}$; por 3 minutos e 20 segundos. Após a irradiação, a solução de PBS foi descartada, sendo posteriormente adicionado com $500 \mu \mathrm{L}$ de meio de cultura DMEM suplementado com $10 \%$ de soro fetal bovino (SFB) e então as células foram incubadas por 24, 48 e 72 horas respectivamente a uma temperatura de $37^{\circ} \mathrm{C}$ e $5 \%$ CO2 (MORAES et al., 2019).

\subsection{Extração de proteínas}

As células foram coletadas por tripsinização para um tubo de $15 \mathrm{~mL}$; adicionouse $1000 \mu \mathrm{L}$ de DMEM; o tubo foi centrifugado em $603,72 \mathrm{~g}$ por 5 minutos; o sobrenadante foi descartado e o pellet ressuspendido com $1000 \mu \mathrm{L}$ de tampão de extração de proteínas (1\% de SDS e 10mM de Tris. $\mathrm{HCl}(\mathrm{pH} 7,4), 50 \mu \mathrm{L}$ de Aprotinina 5 $\mu \mathrm{g} / \mathrm{mL}, 200 \mu \mathrm{L}$ de PMSF $1 \mathrm{mM}, 10 \mu \mathrm{L}$ de Leupeptina $1 \mu \mathrm{g} / \mathrm{mL}$ e 18,9 mg de Ortovanato de sódio 10,28 mM - MP Biomedicals - China) preparado na hora; o tubo foi agitado em vortex por 3 minutos; em seguida, foi agitado em shaker em banho de gelo a $4^{\circ} \mathrm{C}$, por 30 minutos; centrifugado a $12.000 \mathrm{rpm}$ e $4^{\circ} \mathrm{C}$ por 20 minutos; quantificadas utilizando-se o Qubit $^{\circledR}$ "Protein Assay Kit" e a leitura realizada com Qubit Fluorocrometer (Life Technology- Waltham, Massachusetts, EUA) conforme instruções do fabricante; alíquotas de $50 \mu \mathrm{L} /$ tubo; e conservadas a $-80^{\circ} \mathrm{C}$.

\subsection{Gel de proteínas}

Em um tubo de $1 \mathrm{~mL}$ foram adicionados $20 \mu \mathrm{L}$ da amostra e $5 \mu \mathrm{L}$ de tampão de corrida; a solução foi agitada em vortex; aquecida em banho-maria a $70^{\circ} \mathrm{C}$ por 10 minutos. A seguir, as amostras foram aplicadas em gel de poliacrilamida-SDS $10 \%$, pré-fabricado, da Sigma-Aldrich ${ }^{\circledast}$. Como padrão foi utilizado o SeeBlue Plus 2 Prestained da NUPAGE. A solução tampão de corrida foi o MOPS diluído 1:20, e o equipamento foi ajustado para $200 \mathrm{~V}, 140 \mathrm{~mA}$, por 40 minutos. Após a corrida, o gel foi corado Phast Gel Blue R20X, por 2 horas com leve agitação e descorado com solução descolorante (Ácido acético + metanol) por 1 hora com leve agitação. O gel foi fotografado com câmera Kodak Gel Logic 100 Imaging System. A identificação das proteínas foi realizada com base nos parâmetros oferecidos pela Waltham, Massachusetts, EUA, (Figura 1).

\subsection{Imunofluorescência para HSPs}


As células foram plaqueadas com uma lamínula redonda estéril em cada poço; incubadas com DMEM em estufa a $37^{\circ} \mathrm{C}$ com $5 \%$ de $\mathrm{CO}_{2}$, overnigth. Logo após, utilizou-se anticorpos: Anti-HSP27 (produzido em coelho, Sigma-Aldrich ${ }^{\circledR}$ ), Anti-HSP70 (produzido em camundongo, Invitrogen- ThermoFisher Scientific Waltham, Massachusetts, EUA) e Anti-HSP90 (produzido em camundongo, Invitrogen ${ }^{\circledR}$ ), na diluição 1:1000, por 1 hora cada um, a temperatura ambiente e ao abrigo da luz. As células foram lavadas com PBS e incubadas com anticorpos secundários, anti-rabbit (FITC) para HSP27 e anti-mouse (TRICT) para HSP70 e HSP90, diluídos 1:1000, por 30 minutos em temperatura ambiente e ao abrigo da luz. Estão, as lamínulas foram cuidadosamente acomodadas em lâminas estéreis com as células voltadas para baixo e visualizadas em microscópio confocal para captura de imagens pelo software ZEN da Carl ZEISS Microscopy GmbH.

\subsection{Teste de viabilidade celular}

Utilizou-se protocolo adaptado de Feoktistova, Geserick e Leverkus (2016). As células não aderidas foram descartadas da placa de cultura por lavagem com PBS. As células aderidas foram incubadas com $100 \mu \mathrm{L}$ de solução de cristal violeta por 4 minutos. em temperatura ambiente. Depois, a placa foi lavada com água e $200 \mu \mathrm{L}$ de dimetilsulfóxido (DMSO) foram adicionados para incubação por 1 hora antes da leitura em 570 nm utilizando um espectrofotômetro, SpectraCount - Packard - Cole-Parmer Scientific Experts-USA.

\subsection{Análise Estatística}

Os dados do presente relatório foram apresentados na forma de média com desvio padrão, comparados pelo teste de ANOVA two-way e confirmando pelo teste tukey. A significância estatística foi admitida com $P<0,05$ sendo ${ }^{*} P<0,05$; ${ }^{* *} P<0,01$; ${ }^{* * *} P<0,001 ;{ }^{* * *} P<0,0001$ sendo considerado significante. Para a realização das análises estatísticas e gráficos foi utilizado o software GraphPad Prism 6®.

\section{RESULTADOS}

Os resultados do gel de proteínas para as células HEp-2 demonstraram banda proteica próxima à região $90 \mathrm{kDa}$, (Figura 1) indicando presença da proteína de choque térmico HSP90 em células HEp-2. 
Figura 1 - Gel de poliacrilamida após eletroforese das proteínas de choque térmico (HSP) para os tratamentos controle e TFD nos períodos de 24, 48 e 72 horas, capturada pela câmera KODAK ( $\mathrm{P}=$ padrão; 1 =controle 24h; $2=$ TFD 24h; $3=$ controle 48h; 4=TFD 48h; 5=controle 72h; 6=TFD 72h).

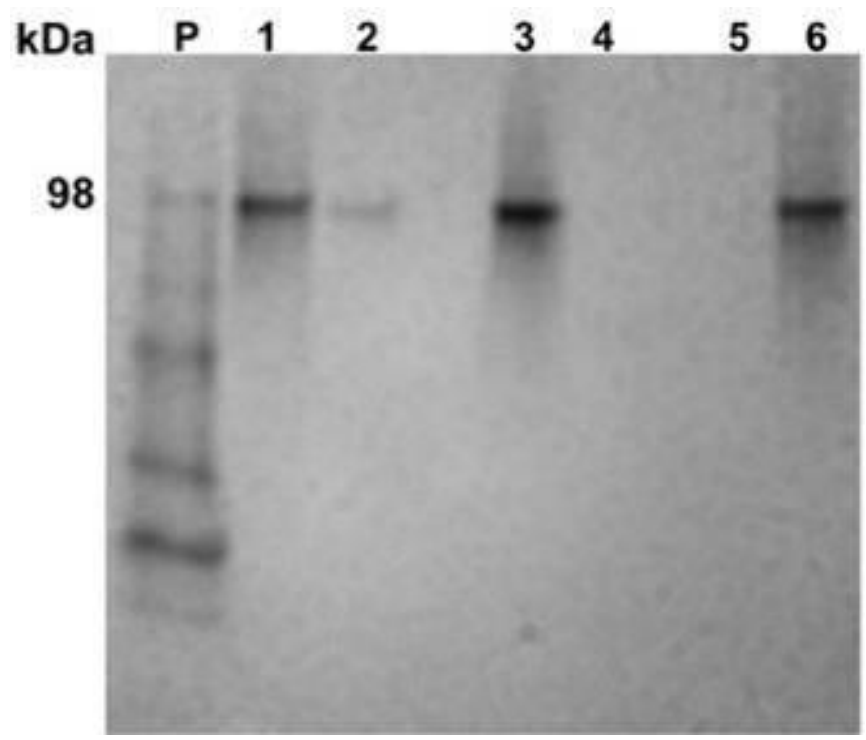

A microscopia confocal confirma a presença das proteínas de choque térmico HSP 27 e 70 como apresentado nas fotomicrografias (Figura 2). 
Figura 2 - Células HEp-2 incubadas com anticorpo anti-HSP27 e anticorpo antiHSP70, e marcadas com DAPI. A- Grupo controle 24 horas (estrela, núcleo; cabeça de seta, marcação positiva para HSP27). B- Grupo terapia fotodinâmica (estrela núcleo;

cabeça de seta, marcação positiva para HSP27 e HSP70). C - Grupo controle 48

horas (estrela, núcleo; cabeça de seta, marcação positiva para HSP70). D- Grupo terapia fotodinâmica (estrela núcleo; cabeça de seta, marcação positiva para HSP27). E- Grupo controle 72 horas (estrela, núcleo). F- Grupo terapia fotodinâmica (estrela núcleo; cabeça de seta, marcação positiva para HSP27), com marcação evidente na região perinuclear.
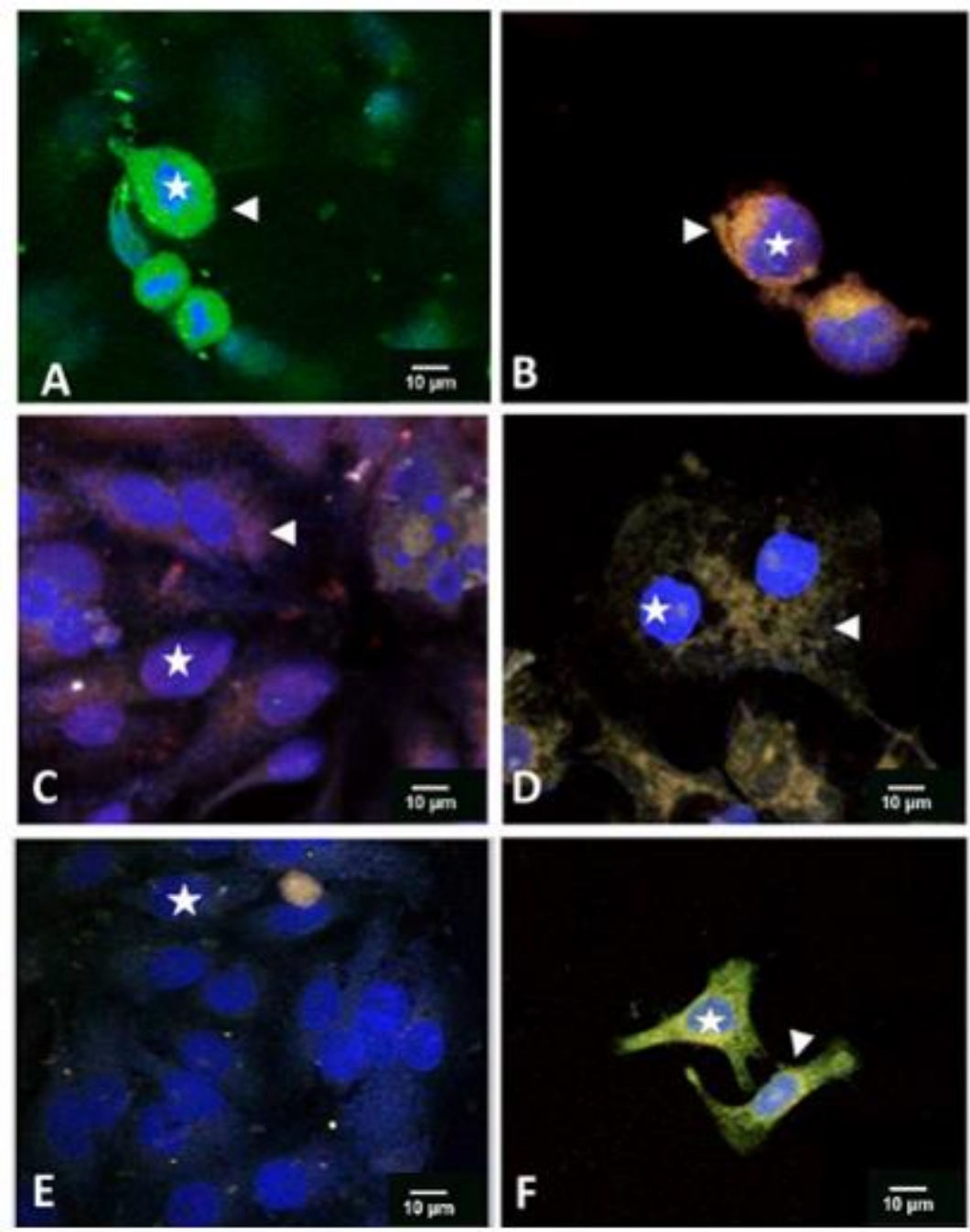

A microscopia confocal nos confirma a presença das proteínas de choque térmico HSP 27 e 70 como apresentado nas fotomicrografias (Figura 3). 
Figura 3 - Células HEp-2 incubadas com anticorpo anti-HSP90, e marcadas com DAPI. A- Grupo controle 24 horas (estrela, núcleo; cabeça de seta, marcação positiva para HSP90). B- Grupo terapia fotodinâmica (estrela, núcleo; cabeça de seta, marcação positiva para HSP90). C - Grupo controle 48 horas (estrela, núcleo; cabeça de seta, marcação positiva para HSP90). D- Grupo terapia fotodinâmica (estrela núcleo; cabeça de seta, marcação positiva para HSP90). E- Grupo controle 72 horas

(estrela, núcleo). F- Grupo terapia fotodinâmica (estrela núcleo; cabeça de seta, marcação positiva para HSP90).
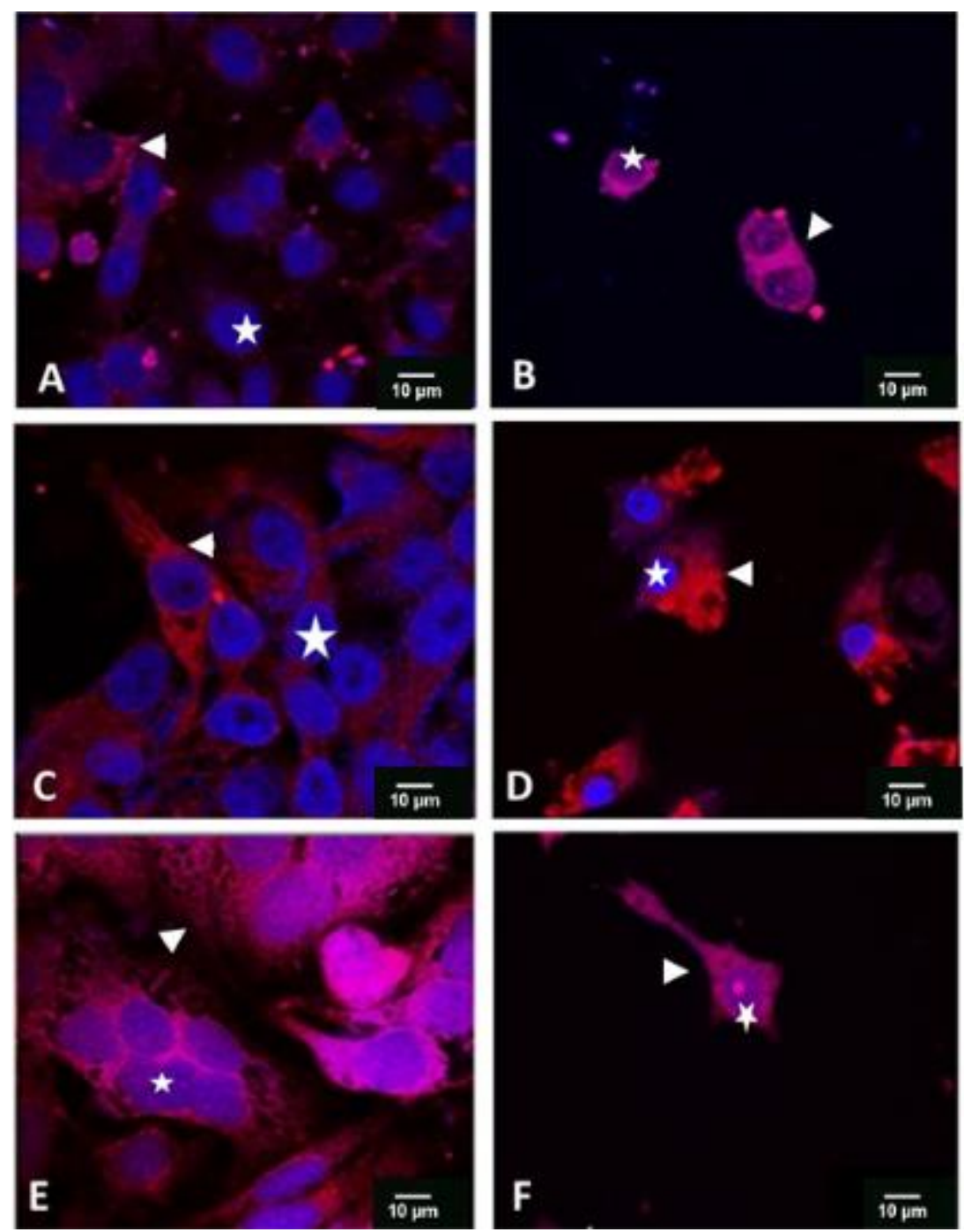

Além da marcação para as HSPs, foi possível notar a redução da população celular, principalmente no tempo de 72 horas, o que se levou a utilizar o teste de cristal violeta para avaliação da atividade celular (Figura 4). 
Figura 4 - Células HEp-2 incubadas com anticorpos anti-HSPs. Células HEp-2 incubadas com anticorpo anti-HSP-27 e anticorpo anti-HSP70, e marcadas com DAPI.

A- Grupo LED 24 horas (estrela, núcleo; cabeça de seta, marcação positiva para HSP27 e HSP70). B- Grupo LED 48 horas (estrela, núcleo; cabeça de seta, marcação positiva para HSP27 e HSP70). C - Grupo LED 72 horas (estrela, núcleo; cabeça de seta, marcação positiva para HSP27). Células HEp-2 incubadas com anticorpo antiHSP-90, e marcadas com DAPI. D- Grupo LED 24 horas (estrela, núcleo, cabeça de seta marcação para HSP90). E Grupo LED 48 horas (estrela, núcleo, seta marcação positiva para HSP90). F- Grupo LED (estrela, núcleo), fraca marcação para HSP90).
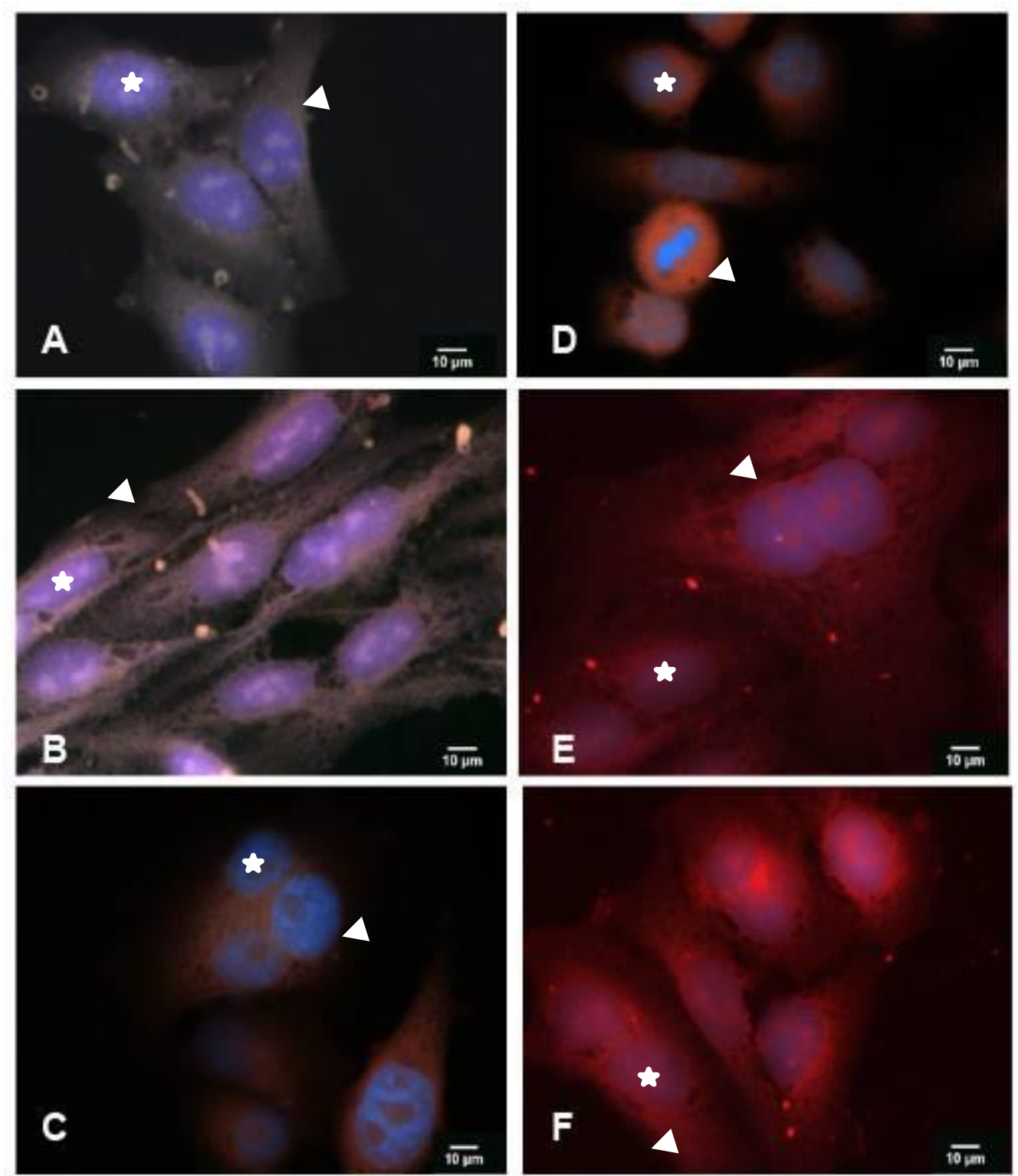
Figura 5 - Células HEp-2 incubadas com anticorpos anti-HSPs. Células HEp-2 incubadas com anticorpo anti-HSP-27 e anticorpo anti-HSP70, e marcadas com DAPI. A- Grupo AIPcS4 24 horas (estrela, núcleo; cabeça de seta, marcação positiva para HSP27 e HSP70). B- Grupo AIPcS4 48 horas (estrela, núcleo; cabeça de seta, marcação positiva para HSP27 e HSP70). C - Grupo AIPcS4 72 horas (estrela, núcleo; cabeça de seta, marcação positiva para HSP27 e HSP70). Células HEp-2 incubadas com anticorpo anti-HSP-90, e marcadas com DAPI. D- Grupo AIPcS4 24 horas (estrela, núcleo), nota-se uma célula em divisão com intensa marcação citoplasmática para HSP90 (cabeça de seta). E- Grupo AIPcS4 48 horas (estrela, núcleo; seta marcação positiva para HSP90). F- Grupo AIPcS4 (estrela, núcleo), com marcação para HSP90 evidente na região perinuclear (cabeça de seta).
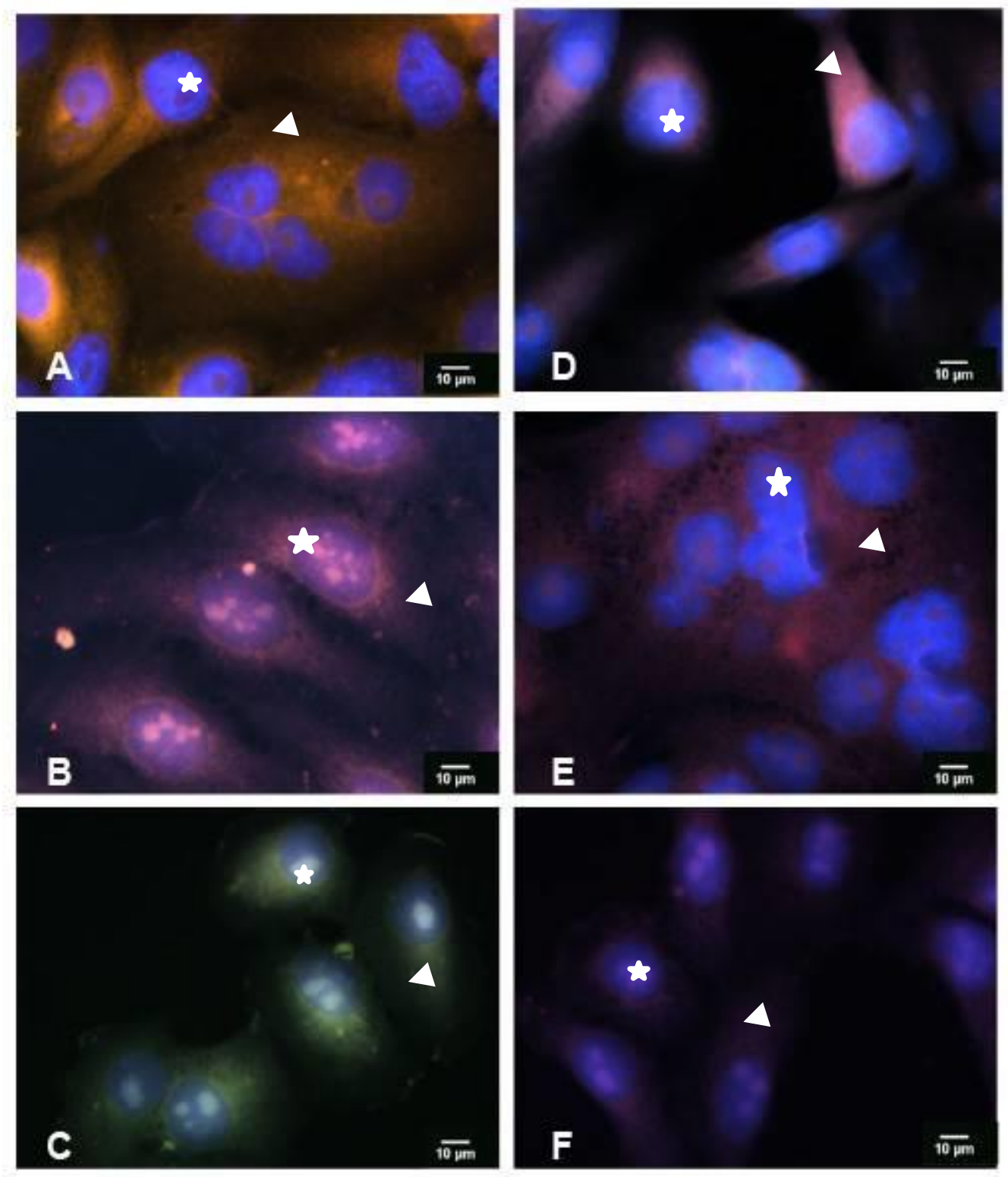
Figura 6 - Teste de cristal violeta, para avaliação da viabilidade celular, no período de 24 horas é possível verificar uma diferença estatística entre o grupo controle e laser com $P=0,001$, já entre o grupo controle e TFD com $P \leq 0,0001$. No período de 48 horas é possível verificar diferença estatística entre o grupo controle e LED e entre o grupo controle e TFD com $\mathrm{P} \leq 0,0001$ para ambos os grupos. Por fim no período de 72 horas é possível verificar diferença estatística entre o grupo controle e LED e entre o grupo controle e TFD com $\mathrm{P} \leq 0,0001$ para ambos os grupos.
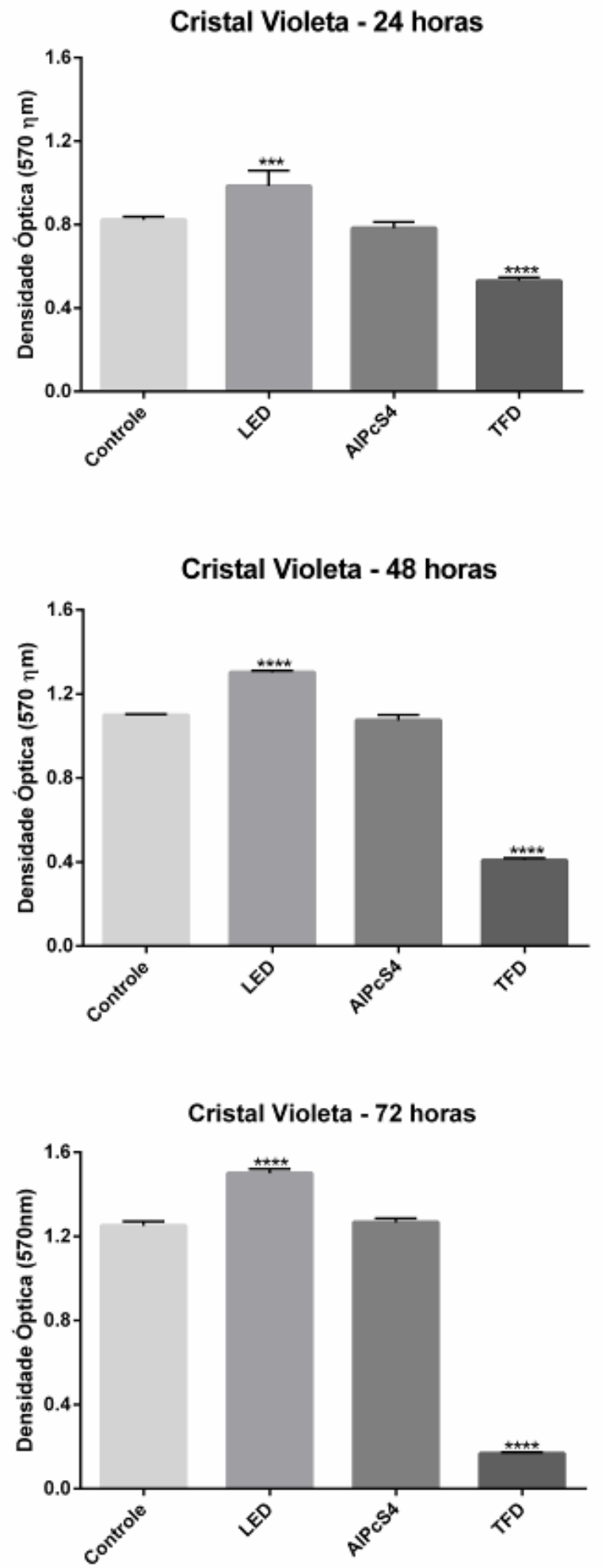
Os resultados obtidos confirmam as observações ao microscópio, sendo observado que no tempo de 24 horas pouca alteração na população celular é vista assim como a marcação negativa para a HSP70 nesse período, enquanto o grupo controle com o passar dos períodos de incubação, apresenta variações na marcação para a HSP27 (24horas), HSP27 e HSP70 em 48 horas e ausência para ambas no período de 72 horas. O grupo LED quando comparado ao grupo controle confirma que a luz acarreta a bioestimulação celular, embora não apresente uma alteração significativa, principalmente no período de 72 horas.

\section{DISCUSSÃO}

Neste estudo, a possível presença de HSP90 no gel de eletroforese no grupo TFD 72 horas foi entendido como uma reação citoprotetora contra o estresse causado pela TFD, ou a busca por sobrevivência em ambiente hostil, já que o meio de cultura não foi renovado e a sua metabolização excessiva pode ter colocado estas células sob estresse. Nesses casos, para reduzir a possibilidade de recidiva tumoral após estresse, alguns estudos demonstram que a utilização de inibidores específicos de HSP são capazes de gerar efeito antitumoral esperado, tanto in vitro como in vivo, promovendo o desarranjo da HSP, impedindo sua ligação a outras moléculas, gerando o acúmulo de citocromo $C$ no citoplasma, ativação das caspases para via apoptótica, formação de EROs, reduzindo a proliferação e a viabilidade celular, inibe a resistência mediada por HSPs, induz resposta imune específica para o antígeno, inibindo a angiogênese e a progressão tumoral (GUERRERO-ROJAS; GUERREROFONSECAZ, 2018; HUANG et al., 2018; LONG et al., 2018; KANEKO et al., 2017; LORENZO; VINTRÓ; MADRID, 2016).

Quando comparados aos grupos controle, onde a presença de HSP27, HSP70 (exceto controle 24 horas) e HSP90 é menor e homogênea no citoplasma, houve intensa marcação dessas HSPs em todos os períodos de tempo após TFD, principalmente localizadas próximas ao núcleo da célula. Ocorrendo marcação positiva dessas HSPs nos grupos $\mathrm{AlPcS}_{4}$ e LED. Como observado por Kostenko e Moens (2009), o aumento da concentração intracelular de HSP27 é decorrente da fosforilação de serina, o que induz seu acúmulo próximo ao núcleo, onde é capaz de alterar o HSF1 (fator de choque térmico 1) (SIMIONI et al., 2009); provocar ubiquitinação e degradação proteossômica (THONEL et al., 2010); inibir a síntese proteica e a tradução de RNAm (GRACEFFA, 2011). Logo, pode-se dizer que a elevada concentração de HSP27 próxima ao núcleo das células neste estudo, pode ser considerada uma causa importante para gerar alterações na homeostasia intracelular.

Acredita-se que a HSP27 regule a apoptose mantendo o equilíbrio redox da célula, inibe a apoptose aumentando o nível intracelular da glutationa antioxidante (GSH), inibindo a liberação do citocromo $\mathrm{C}$ mitocondrial ou ligando-se diretamente a ao citocromo C (KALMAR; GREENSMITH, 2009). Os efeitos da HSP27 na indução ou atenuação da morte celular após a TFD dependerão das condições de tratamento 
fotodinâmico, do fotossensibilizante e / ou do tipo de célula cancerígena (RODRÍGUEZ et al., 2015). A quercetina, um inibidor de HSP27 estudado em ensaios clínicos, é um bioflavonoide conhecido por ter atividade antitumoral por desencadear a apoptose, inibindo a função citotoproteira que a HSP27 proporciona a célula de câncer (COHENSFADY, 2009). Por isso, é comum o uso da quercetina com o objetivo de melhorar a resposta ao tratamento.

A presença de HSP70 pode inibir várias vias de morte celular, incluindo a apoptose intrínseca, levando a resistência à TFD (RODRÍGUEZ et al., 2016). Entretanto, a HSP70 pode se ligar ao fator indutor de apoptose (AIF), levando à inibição da apoptose independente de caspase (EVANS; CHANG; GESTWICKI, 2010). $\mathrm{Na}$ TFD é indutora de apoptose, tendo como uma das vias a translocação das HSP70 do citoplasma para a superfície celular, onde pode ser liberada no meio, como resposta do impacto da terapia, estando relacionada à ruptura mitocondrial ou estresse superficial direto, e sua a principal função é estabilizar a integridade da membrana plasmática (RODRíGUEZ et al., 2016). No entanto, sob tratamento letal com TFD, a HSP70 não consegue prevenir a apoptose e, contrariamente, promove a morte celular imunogênica (GUO, 2004).

A HSP90 aumenta a via de sobrevivência regulada pela proteína quinase $B$ (conhecida do inglês como Akt), reduzindo a via apoptótica intrínseca. A inibição da HSP90 libera Apaf-1 para interagir com a caspase-9 e induzir a cascata apoptótica pela ativação da procaspase-3 (PANZARINI; INGUSCIO; DINI, 2013). Os inibidores de HSP90 estão sendo desenvolvidos como agentes anticancerígenos e mostraram bons resultados em tumores sólidos e algumas malignidades hematológicas (RODRÍGUEZ et al., 2016).

Nos estudos de Kim et al. (2012), os resultados obtidos foram pró-tumorais, mostrando que a redução de HSP27 após TFD restaurou a sobrevivência celular por estimular a autofagia e atenuou a apoptose por inibir a via mediada por caspases. Outro estudo realizado por Kim e colaboradores (2016), investigando HSP27, HSP70 e HSP90 após TFD em câncer de cabeça e pescoço, observaram que houve redução de HSP27 e aumento de HSP70 e HSP90, o que resultou em aumento da sobrevida. A regulação negativa da expressão de HSP27 induz autofagia por meio de LC3II em células resistentes a TFD (KIM et al., 2016). Assim como citado por Broekgaarden et al. (2015), as propriedades citoprotetoras das HSPs após a TFD provavelmente surgem do estresse proteotóxico resultante da oxidação de proteínas. Isso justifica o aumento na produção de HSPs em células expostas à TFD em busca da sobrevivência celular que, possivelmente, resultará em uma resistência à terapia. Então, avaliando desta forma, torna-se interessante a utilização de agentes inibidores específicos para as HSPs, impedindo sua produção e a resistência à TFD.

Fato é que não há uma concordância. Helbig, Simon e Paasch (2011) dizem que a inibição das HSPs seria benéfica para o desfecho da TFD, dado o papel das HSPs 
na sobrevivência das células tumorais. Já para Jego et al. (2013), inibir as HSPs pode ser prejudicial, dada sua atuação na resposta imune antitumoral, como por exemplo na utilização exclusiva de inibidores de HSP90, que aumentam o estresse proteotóxico, causando um aumento na produção de HSP70, a qual, neste caso, pode minimizar qualquer efeito benéfico deste agente na morte de células tumorais. Ao que Schlecht et al. (2013) sugerem, assim, utilizar agentes inibidores de HSPs concomitantemente, para que a eficácia da TFD seja obtida, bem como o uso de inibidores de fatores de transcrição para as proteínas de choque térmico, também parecem fornecer abordagens promissoras para a eficácia da TFD (YOON et al., 2010).

Os grupos AlPcS4 e LED marcados com HSP27, HSP70 e HSP90, apresentaram marcação positiva para as proteínas. Entretanto quando analisamos o tempo de 72 horas do grupo LED, nota-se a prevalecendo a marcação para HSP27, enquanto HSP90 apresenta marcação menos intensa.

Já o ensaio colorimétrico com o Cristal Violeta avalia a interação de um corante básico e sua incorporação às estruturas celulares que possuem carga negativa, como por exemplo, o DNA e a membrana plasmática da célula de estudo, fornecendo assim a quantificação da citotoxicidade celular, sendo isso proporcional à densidade da colocação, servindo a aferir a viabilidade celular (RAMOS, 2016).

Os resultados obtidos no ensaio com Cristal Violeta demonstraram resultados promissores, visto que causa a morte das células de câncer HEp-2 no período de 24 horas (Figura 6), persistindo a diminuição da população de células nos períodos de 48 e 72 horas. Este resultado esta em concordância com Moraes et al. (2019) no qual também verificou que os efeitos da TFD não são somente no momento da irradiação, mas que perduram devido a produção das EROs causando danos a diversas subestruturas célulares como o núcleo e DNA (MORAES et al., 2019), mitocôndria e citoesqueleto (MAFTOUMCOSTA et al., 2008), alterações morfológicas (Fontana et al., 2017), mudanças no padrão protético (OLSEN et al., 2017), encaminhando para a morte celular (ROBERTSON; EVANS; ABRAHAMSE, 2009), estes eventos podem estar relacionados com a ativação das HSPs para o reparo celular (GUERREROROJAS; GUERRERO-FONSECAZ, 2018).

Outro ponto que deve ser destacado no ensaio de cristal violeta é a ação da irradiação nas células (grupo LED), visto que aumentou a população de células (Figura 6) nos períodos de 24, 48 e 72 horas, demonstrando o efeito de biomodulação do LED nas células. Isto deve-se a esse tipo de terapia, pois ela promove efeitos fotoquímicos, fotofísicos e fotobiológicos em células e tecidos, sem elevar a temperatura acima de $36.66^{\circ} \mathrm{C}\left(98^{\circ} \mathrm{F}\right)$. Acredita-se que o efeito da biomodulação nas células e tecidos ocorre devido à absorção da energia luminosa pelos fotorreceptores endógenos (MIGLIORATI et al., 2013). Estudos revelaram que os receptores fotoativados primários são componentes da cadeia respiratória celular. A ativação desses receptores pode levar à estimulação ou inibição do metabolismo celular, dependendo 
da dose energética da luz (KOCAMAN et al., 2014). Doses de baixa energia poderiam regular a produção de espécies reativas de oxigênio. A luz visível pode levar a alterações fotoquímicas nos fotorreceptores na mitocôndria, alterando o metabolismo celular e produzindo um efeito de transdução em outros componentes celulares (efeito de biomodulação) (KARA et al., 2018). Outros sugerem que este efeito é devido a alterações fotofísicas nos canais de $\mathrm{Ca}^{++}$na membrana celular, melhorando a proporção de íons nas células (BASSO et al., 2015).

\section{CONCLUSÃO}

Concluiu-se que HSP27, HSP70 e HSP90 são produzidas em células HEp-2, tanto na população de células não tratadas como na população de células tratadas com TFD, sendo expressas abundantemente em células HEp-2 após TFD. A terapia se mostrou eficaz devido à redução do número de células, apresentando-se como uma alternativa ao tratamento do carcinoma de laringe humano. Porém, dada a heterogeneidade do comportamento e das funções das HSPs, mais estudos são necessários para confirmar a relação entre a expressão de HSPs e a resposta fotodinâmica. A irradiação LED não acarreta alterações significativas na marcação de HSPs 27,70 e 90.

\section{AGRADECIMENTOS}

Agradecimentos a FAPESP pelo auxilio no 2016/17984-1 e a Coordenação de Aperfeiçoamento de Pessoal de Nível Superior - Brasil (CAPES) - Código de Financiamento 001.

\section{REFERÊNCIAS}

AGOSTINIS, P. et al. Photodynamic therapy of cancer: An update. CA: A Cancer Journal for Clinicians, v. 61, n. 4, p. 250-281, 2011.

BASSO, F. G., PANSANI, T. N., SOARES, D. G., SCHEFFEL, D. L., BAGNATO, V. S., DE, SOUZA COSTA, C. A. and HEBLING, J. Biomodulation of Inflammatory Cytokines Related to Oral Mucositis by Low-Level Laser Therapy. Photochem Photobiol, v. 91, n. 4, p. 952-956, 2015. doi:10.1111/php.12445.

BLUM, J. S.; WEARSCH, P. A.; CRESSWELL, P. Pathways of Antigen Processing. Annual Review of Immunology, v. 31, n. 1, p. 443-473, 2013.

BROEKGAARDEN, M. et al. Tumor cell survival pathways activated by photodynamic therapy: a molecular basis for pharmacological inhibition strategies. Cancer and Metastasis Reviews, v. 34, n. 4, p. 643-690, 2015.

BUTTROS, D. A. B. Associação das HSP 60 e 70 com fatores de risco cardiovascular em mulheres na pós-menopausa tratadas de câncer de mama. 2018. Tese (Doutorado) - Universidade Estadual Paulista Júlio de Mesquita Filho, 
Botucatu - SP, 2018. Disponível em:

<https://repositorio.unesp.br/handle/11449/154253>. Acesso em: 26 fev. 2019.

CALDERWOOD, S. K. Heat shock proteins in breast cancer progression-A suitable case for treatment? International Journal of Hyperthermia, v. 26, n. 7, p. 681- 685, 2010.

CASAS, A. et al. Mechanisms of Resistance to Photodynamic Therapy. Current Medicinal Chemistry, v. 18, n. 16, p. 2486-2515, 2011.

COHEN-SFADY, M. et al. Heat Shock Protein 60, via MyD88 Innate Signaling, Protects B Cells from Apoptosis, Spontaneous and Induced. The Journal of Immunology, $v$. 183, n. 2, p. 890-896, 2009.

ETMINAN, N. et al. Modulation of migratory activity and invasiveness of human glioma spheroids following 5-aminolevulinic acid-based photodynamic treatment. Journal of Neurosurgery, v. 115, n. 2, p. 281-288, 2011.

EVANS, C. G.; CHANG, L.; GESTWICKI, J. E. Heat Shock Protein 70 (Hsp70) as an Emerging Drug Target. Journal of Medicinal Chemistry, v. 53, n. 12, p. 4585-4602, 2010.

FEOKTISTOVA, M., GESERICK, P. AND LEVERKUS, M. Crystal Violet Assay for Determining Viability of Cultured Cells. Cold Spring Harbor Protocols, n. 4, 2016, pdb.prot087379. https://doi.org/10.1101/pdb.prot087379

GRACEFFA, P. Hsp27-Actin Interaction. Biochemistry Research International, v. 2011, p. 1-7, 2010.

GRANER, M. W. et al. Endoplasmic Reticulum Chaperones and Their Roles in the Immunogenicity of Cancer Vaccines. Frontiers in Oncology, v. 4, 2015.

GUERRERO-ROJAS, R; GUERRERO-FONSECAZ, C. Mecanismos moleculares de las proteínas de choque térmico (HSPs) implicados en el desarrollo neoplásico. Salud Uninorte. v. 34, n. 2, p. 455-474, 2018. Disponível em:

<http://rcientificas.uninorte.edu.co/index.php/salud/article/view/7160/214421443 429> Acesso em: 26 fev. 2019.

GUO, F. Mechanistic role of heat shock protein 70 in Bcr-Abl-mediated resistance to apoptosis in human acute leukemia cells. Blood, v. 105, n. 3, p. 1246-1255, 2004.

HELBIG, D.; SIMON, J. C.; PAASCH, U. Photodynamic therapy and the role of heat shock protein 70. International Journal of Hyperthermia, v. 27, n. 8, p. 802-810, 2011.

HUANG, L. et al. A tumor-targeted Ganetespib-zinc phthalocyanine conjugate for synergistic chemo-photodynamic therapy. European Journal of Medicinal Chemistry, v. 151, 294-303, 2018.

ISSA, MCA; MANELA-AZULAY, M. Terapia fotodinâmica: revisão da literatura e documentação iconográfica. Anais Brasileiros de Dermatologia, v. 85, n. 4, p. 501$511,2010$.

JEGO, G. et al. Targeting heat shock proteins in cancer. Cancer Letters, v. 332, n. 2, p. 275-285, 2013. 
JUHASZ, K. et al. The Complex Function of Hsp70 in Metastatic Cancer. Cancers, v. 6, n. 1, p. 42-66, 2013.

KALMAR, B; GREENSMITH, L. Induction of heat shock proteins for protection against oxidative stress. Advanced Drug Delivery Reviews, v. 61, n. 4, p. 310-318, 2009.

KANEKO, K. et al. Induction of enhanced tumor-specific immunity by Hsp90 targeted photodynamic therapy (Hsp90-PDT) combined with immune checkpoint inhibition. AACR Annual Meeting, Washington, 2017.

KAPOOR, C.; VAIDYA, S. Heat shock protein (HSP) and cancer: an overview. Am. J. Med. Dent. Sci., v. 1, n. 1, p. 31-34, 2013.

KARA, C, SELAMET, H, GÖKMENOĞLU, C, KARA, N. Low level laser therapy induces increased viability and proliferation in isolated cancer cells. Cell Prolif. v. 51, n. 2, e12417, 2018. https://doi.org/10.1111/cpr.12417

KHALIL, A. A. et al. Heat shock proteins in oncology: Diagnostic biomarkers or therapeutic targets? Biochimica et Biophysica Acta (BBA) - Reviews on Cancer, v. 1816, n. 2, p. 89-104, 2011.

KIM, J. et al. Effects of HSP27 downregulation on PDT resistance through PDTinduced autophagy in head and neck cancer cells. Oncology Reports, v. 35, n. 4, p. 2237-2245, 2016.

KIM, J. et al. Down-regulation of heat-shock protein 27-induced resistance to photodynamic therapy in oral cancer cells. Journal of Oral Pathology \& Medicine, v. 42, n. 1, p. 9-16, 2012.

KOCAMAN G, BELDÜZ N, ERDOGAN C, OZBEK E, SADIK E, KARA C. The use of surgical Nd:YAG laser in an oral pyogenic granuloma: a case report. J Cosmet Laser Ther. v.16, n. 4, p. 197-200, 2014.

KOSTENKO, S.; MOENS, U. Heat shock protein 27 phosphorylation: kinases, phosphatases, functions and pathology. Cellular and Molecular Life Sciences, v. 66, n. 20, p. 3289-3307, 2009.

KUMAR, S. et al. Targeting Hsp70: A possible therapy for cancer. Cancer Letters, v. 374 , n. 1, p. 156-166, 2016.

LI, Y. et al. Nanotechnology-based photoimmunological therapies for cancer. Cancer Letters, v. 442, p. 429-438, 2019.

LONG, Q. et el. Image-guided photo-therapeutic nanoporphyrin synergized HSP90 inhibitor in patient-derived xenograft bladder cancer model. Nanomedicine:

Nanotechnology, Biology and Medicine, v. 14, n. 3, p. 789-799, 2018.

LORENZO, J. G.; VINTRÓ, X. L.; MADRID, M. C. P. Expresión de Heat Shock Protein90 (HSP-90) como factor predictor de la respuesta a radioterapia en pacientes con tumores de cabeza y cuello. Acta Otorrinolaringológica Española, v. 67, n. 3, p. 130-134, 2016. 
LU, X.; KAKKAR, V. The Role of Heat Shock Protein (HSP) in Atherosclerosis:

Pathophysiology and Clinical Opportunities. Current Medicinal Chemistry, v. 17, n. 10, p. 957-973, 2010.

MAFTOUM-COSTA, M., NAVES, K. T., OLIVEIRA, A. L., TEDESCO, A. C., DA, SILVA, N. S. AND PACHECO-SOARES, C. Mitochondria, endoplasmic reticulum and actin filament behavior after PDT with chloroaluminum phthalocyanine liposomal in HeLa cells. Cell Biology International, v. 32, n. 8, p. 1024-1028. 2008, doi:10.1016/j.cellbi.2008.04.005

MIGLIORATI C., HEWSON I. et al. Systematic review of laser and other light therapy for the management of oral mucositis in cancer patients. Supportive Care in Cancer, v. 21, n. 1, p. 333-341, 2013.

MORAES, C. D. G. O. et al. Genotoxic effects of photodynamic therapy in laryngeal cancer cells - An in vitro study. Experimental Biology and Medicine, v. 244, n. 3, p. 262-271, 2019.

MULLER, C. H. L. Resposta ao choque térmico e da razão HSPA1A extra/intraceluar em leucócitos de indivíduos idosos e de meia idade submetidos a treinamento de força. 2018. Dissertação (Mestrado) - Universidade Federal do Rio Grande do Sul, Porto Alegre, 2018. Disponível em: <https://www.lume.ufrgs.br/bi tstream/handle/10183/174954/001063817.pdf? sequence=1\&isAllowed=y> Acesso em: 26 fev. 2019.

OLSEN J.G., TEILUM K et al. Behaviour of intrinsically disordered proteins in proteinprotein complexes with an emphasis on fuzziness. Cellular and Molecular Life Sciences, v. 74, n. 17, p. 3175-3183, 2017.

PANZARINI, E.; INGUSCIO, V.; DINI, L. Immunogenic Cell Death: Can It Be Exploited in PhotoDynamic Therapy for Cancer? BioMed Research International, v. 2013, p. 118, 2013.

RADONS, J. The human HSP70 family of chaperones: where do we stand? Cell Stress and Chaperones, v. 21, n. 3, p. 379-404, 2016.

RAMOS, L. P. Atividade antimicrobiana e citotoxicidade dos extratos glicólicos de Pfaffia paniculata e Juglans regia L. São José dos Campos: [s.n.], 2016.

ROBERTSON CA, EVANS DH, ABRAHAMSE H. Photodynamic therapy (PDT): a short review on cellular mechanisms and cancer research applications for PDT. $\mathbf{J}$ Photochem Photobiol B, v. 96, n.1, p. 1-8, 2009.

RODRÍGUEZ, M. E. et al. Heat shock proteins in the context of photodynamic therapy: autophagy, apoptosis and immunogenic cell death. Photochemical \&

Photobiological Sciences, v. 15, n. 9, p. 1090-1102, 2016.

SCHLECHT, R. et al. Functional Analysis of Hsp70 Inhibitors. PLoS ONE, v. 8, n. 11, 2013.

SEIGNEURIC, R. et al. Heat Shock Proteins as Danger Signals for Cancer Detection. Frontiers in Oncology, v. 1, 2011.

SILVA, A.C.P. et al. Atividade fotodinâmica e conceitos: um experimento demonstrativo. Quim. Nova, v. 41, n. 6, 706-712, 2018. 
SILVA, D.F. Alternativas para otimização da ação fotodinâmica no tratamento de câncer superficial. 2014. Tese (Doutorado) Escola de Engenharia de São Carlos, Universidade de São Paulo, São Carlos-SP, 2014. Disponível em:

<http://www.teses.usp.br/teses/disponiveis/18/18158/tde-10022015-100102/en.php>. Acesso em: 26 fev. 2019.

SIMIONI, M. B. et al. Heat shock protein 27 is involved in SUMO-2/3 modification of heat shock factor 1 and thereby modulates the transcription factor activity. Oncogene, v. 28, n. 37, p. 3332-3344, 2009.

SONG, C. H. et al. Potential prognostic value of heat-shock protein 90 in the presence of phosphatidylinositol-3-kinase overexpression or loss of PTEN, in invasive breast cancers. Breast Cancer Research, v. 12, n. 2, 2010.

SRIVASTAVA, P. Interaction of heat shock proteins with peptides and antigen presenting cells: Chaperoning of the Innate and Adaptive Immune Responses. Annual Review of Immunology, v. 20, n. 1, p. 395-425, 2002.

STANGL, S. et al. Targeting membrane heat-shock protein 70 (Hsp70) on tumors by $\mathrm{cmHsp} 70.1$ antibody. Proceedings of the National Academy of Sciences, v. 108, n. 2, p. 733-738, 2010.

TAIPALE, M.; JAROSZ, D.F.; LINDQUIST, S. HSP90 at the hub of protein homeostasis: emerging mechanistic insights. Nature Reviews Molecular Cell Biology, v. 11, n. 7, p. 515-528, 2010.

TERRINCA, J. M. A. Papel das Proteínas de Choque Térmico na apoptose mediada por Espécies Reativas de Oxigénio em culturas celulares. 2015. Dissertação (Mestrado) - Universidade do Algarve, Portugal, 2015. Disponível em: <https://sapientia.ualg.pt/handle/10400.1/7626>. Acesso em: 26 fev. 2019.

THONEL, A. et al. HSP27 controls GATA-1 protein level during erythroid cell differentiation. Blood, v. 116, n. 1, p. 85-96, 2010.

TÓTH, M.E.; GOMBOS, I.; SÁNTHA, M. Heat shock proteins and their role in human diseases. Acta Biologica Szegediensis, v. 59 (suppl.1), p. 121-141, 2015.

VAN STRATEN, D. et al. Oncologic Photodynamic Therapy: Basic Principles, Current Clinical Status and Future Directions. Cancers, v. 9, n. 12, 2017.

WOZNIAK, M. et al. The effect of in vitro photodynamic therapy on increase of osteopontin and heat shock protein 70 expression in squamous cell and colon carcinoma. IEEE Journal of Selected Topics in Quantum Electronics, v. 1-1, 2018.

YOON, Y. J. et al. KRIBB11 Inhibits HSP70 Synthesis through Inhibition of Heat Shock Factor 1 Function by Impairing the Recruitment of Positive Transcription Elongation Factor $b$ to thehsp70Promoter. Journal of Biological Chemistry, v. 286, n. 3, p. 17371747, 2010. 